\title{
Evaluation, Identification \& Control of Ergonomic Risk Factors in Electronics Companies (Case Study Engineering Company Behpajooh)
}

\author{
Fatemeh Hashempour ${ }^{1}$, Naser Sadra Abarghouei ${ }^{2 *}$
}

1. MSc Student of Industrial Safety Engineering, University of Science and Arts, Yazd, Iran

2. Faculty Member, Department of Industry and Technology, University of Applied Sciences and Technology, Yazd, Iran

\begin{tabular}{|c|c|}
\hline Article Info & ABSTRACT \\
\hline $\begin{array}{c}\text { Original Article } \\
\text { Received: 05 Jan 2018; } \\
\text { Accepted: 13 March. 2018; } \\
\text { Published Online 2018/05/09 } \\
\text { DOI: 10.30699/jergon.5.4.1 } \\
\text { Use your device to scan } \\
\text { and read the article online }\end{array}$ & $\begin{array}{l}\text { Background: The design and manufacturing process in electronic companies is } \\
\text { the most time consuming work behind computers. Because of the high prevalence of } \\
\text { musculoskeletal disorders in computer users, researchers need to identify risk factors } \\
\text { and ergonomic problems and ways to reduce them. } \\
\text { Methods: This study was a descriptive-analytical study and was conducted as an } \\
\text { intervention in Behpajooh engineering company in Isfahan. Statistical sampling was } \\
\text { done by global sampling ( } 31 \text { people). The Nordic questionnaire and the Rapid Office } \\
\text { Strain Assessment (ROSA) were used to evaluate the risk factors of ergonomics. } \\
\text { Data analysis was performed by using McNemar and Wilcoxon's non-parametric } \\
\text { tests and using SPSS software. } \\
\text { Results: The results of the Nordic questionnaire, before ergonomic intervention, } \\
\text { the frequency of problems in elbow is zero, in waist, upper back, neck and shoulders } \\
\text { is } 45-38 \% \text {. Evaluation of Ergonomic Risk Factors derived from the Rapid Office } \\
\text { Strain Assessment before intervention showed } 35.5 \% \text { (11 people) at low risk, } 38.7 \% \\
\text { (12 people) in the warning zone and } 25.8 \% \text { ( } 8 \text { people) in the area requiring ergonomic } \\
\text { intervention. Statistical analysis of ergonomic interventions showed that the number } \\
\text { of people in the area of warning and necessity are less than the number of people } \\
\text { before intervention. } \\
\text { Conclusion: The most musculoskeletal disorders were reported in the neck, } \\
\text { lower back, upper back and shoulders. Statistical results after ergonomic intervention } \\
\text { indicate a decrease in these disorders. The results led to the understanding that the } \\
\text { risks in electronic companies could be reduced by ergonomic interventions. } \\
\text { Implementation of ergonomic interventions based on engineering, management and } \\
\text { educational proceeding can be effective in reducing musculoskeletal disorders. } \\
\text { Keywords: Ergonomic Risk Factors, Ergonomic Interventions, Electronic Companies, Rapid } \\
\text { Office Strain Assessment (ROSA) }\end{array}$ \\
\hline I & $\begin{array}{l}\text { erms of the Creative Commons Attribution-noncommercial } 4.0 \\
\text { cial usages, provided the original work is properly cited. }\end{array}$ \\
\hline
\end{tabular}

How to Cite This Article:

Hashempour F, Sadra Abarghouei N. Evaluation, Identification \& Control of Ergonomic Risk Factors in Electronics Companies (Case Study Engineering Company Behpajooh) . J Ergon. 2018; 5 (4): 1-8 


\section{مقالله يزوهشى}

ارزيابى، شناسايى و كنترل ريسك فاكتورهاى ارگَونوميكى در شركتهاى الكترونيكى

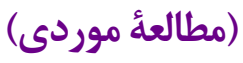

فاطمه هاشم يور'، ناصر صدرا ابرقويى

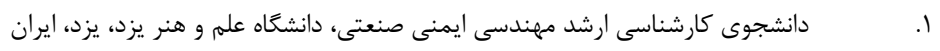

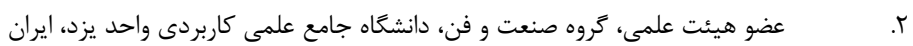

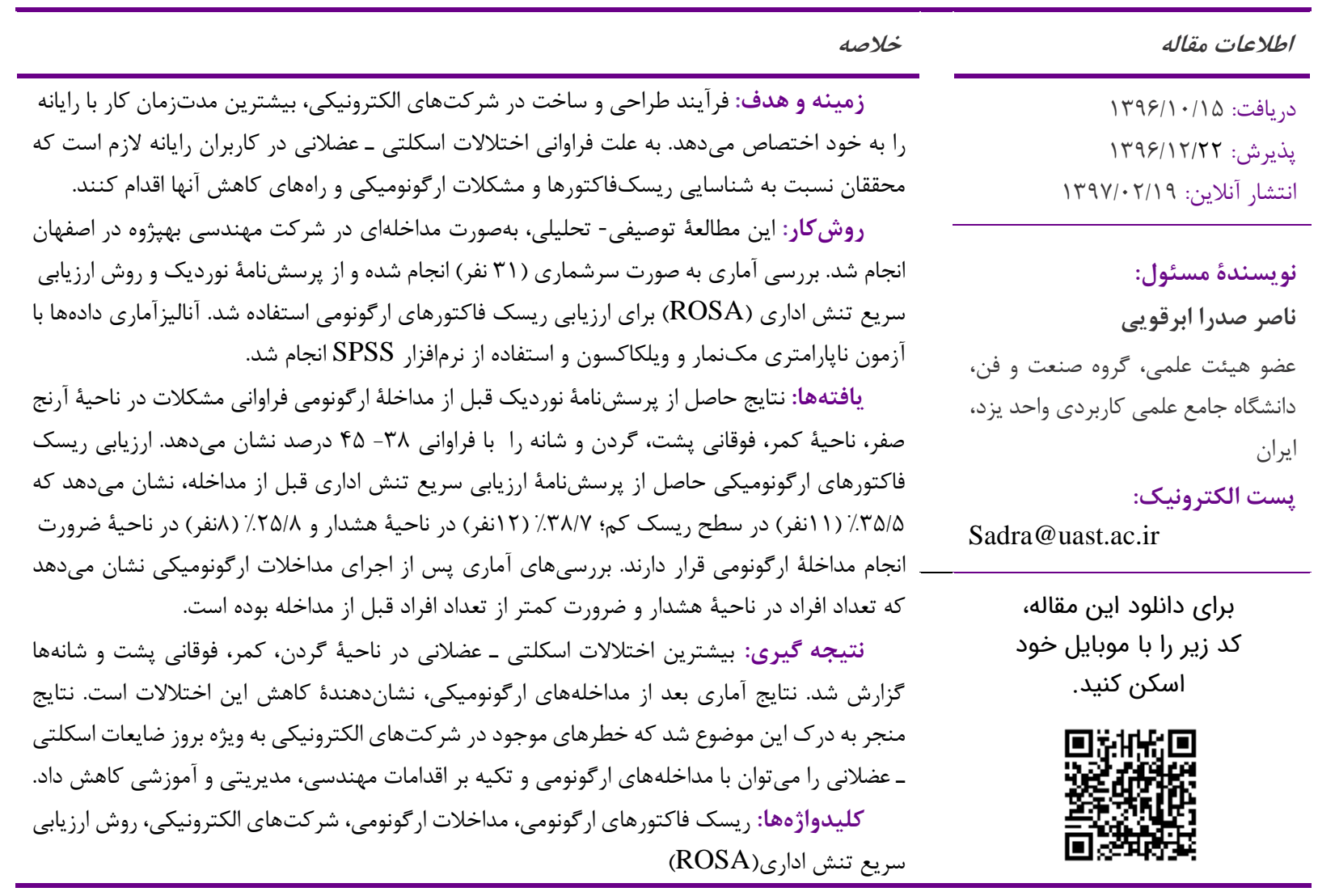

مقدمه

ضمن انجام كار و توجهنكردن به ارَّونومى و استرس شغلى،

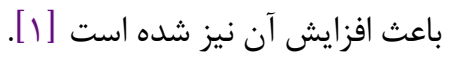

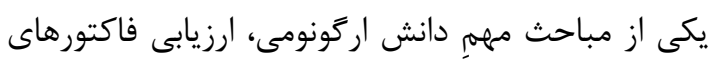
موثر در ايجاد اختلالات اسكلتى ـ عضلانى ناشى از كار (Work-related Musculoskeletal Disorders-WMSDs) است. اختلالات اسكلتى ـ عضلانى مرتبط با كار معمولاً باعث درگيرى كمر، ستون فقرات گردنى و اندامهاى فوقانى مىشود. اين اختلالات شايعترين بيمارىها و آسيبهاى شغلى

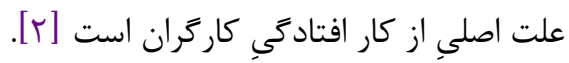

استفاده از رايانه در كشورهاى در حال توسعه اگرجه باعث تسريع در انجام كارها و صرفهجويى در زمان، انرزى و منابع

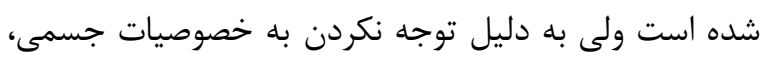
روانى و اجتماعى كاربران، آثار سوء بسيارى در بروز اختلالات

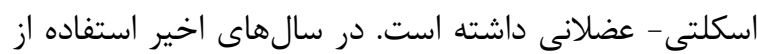
رايانه براى هر كارى ضرورى بوده و كمتر شغلى را مىتوان بيدا

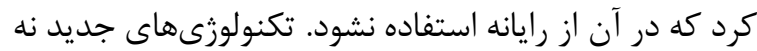
فقط اختلالات اسكلتى ـ عضلانى ناشى از كار را كاهش نداده

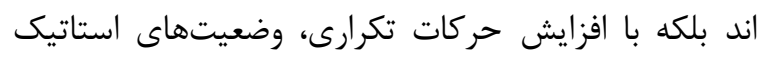


وسيعى براى شناسايى و ييشگيرى از بروز اين آسيبها و

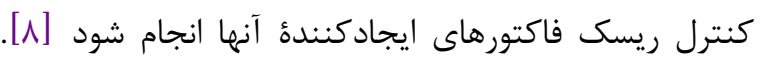

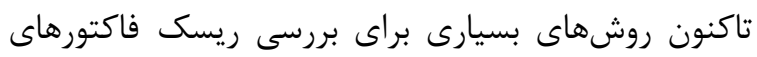

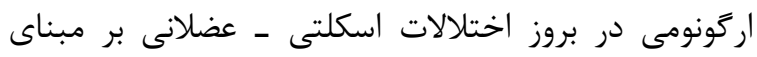

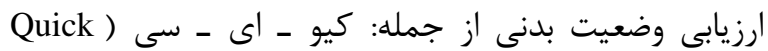
Rapid Upper Limb (Exposure Checklist- QEC Rapid Entire Body) و و ربال (Assessment -RULA (Assessment- REBA يكى از روشهاى جديدى كه در مقايسه با ديخر روشهاى

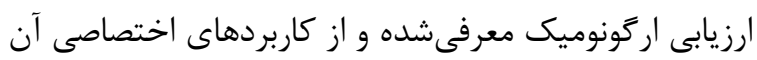

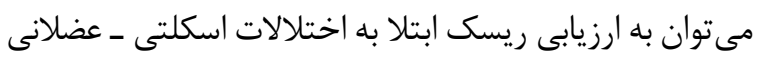

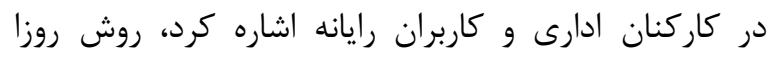
(Rapid Office Strain Assessment-ROSA) روش ريسك فاكتورهاى اركونوميكى در كاركنان ادارى كه

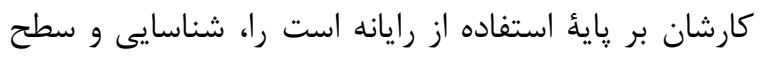

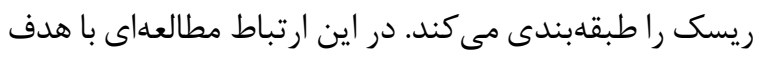

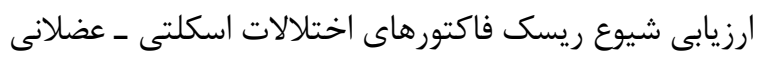

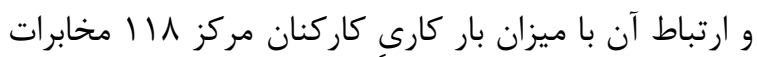

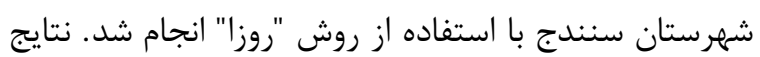

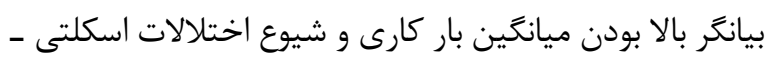

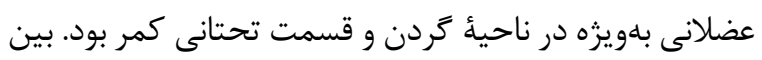
متغيرهاى جنسيت، شاخص توده بدنى، شيفت كارى، سابقئ

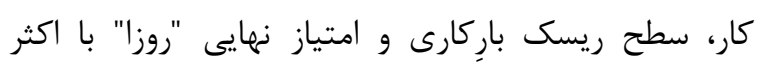

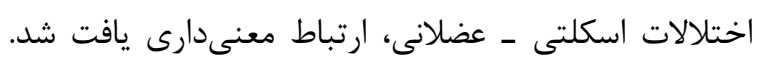

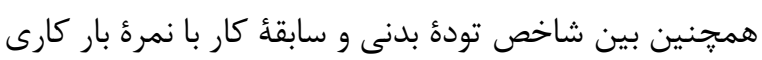

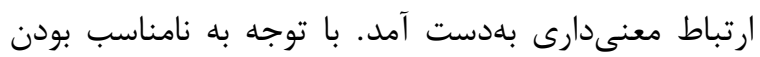

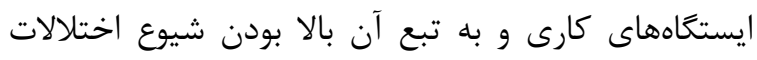

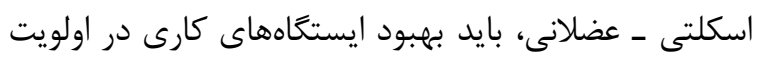

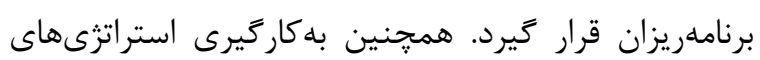

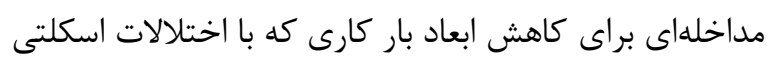

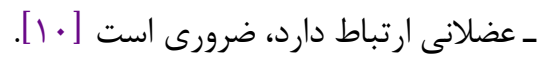

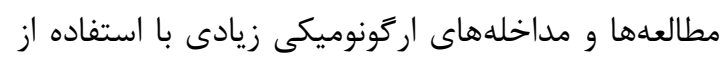

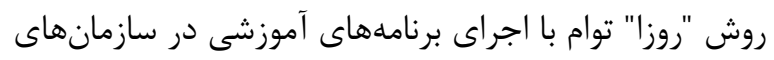

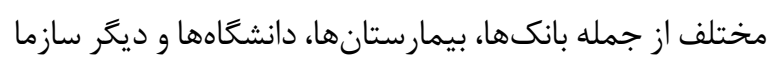

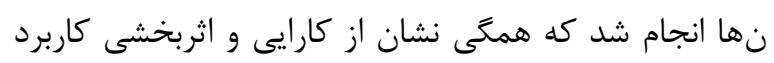

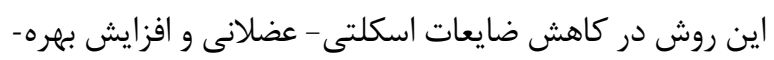

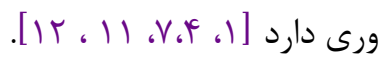

مهمهرين مشكلات ناشى از استفادء نادرست از رايانه،

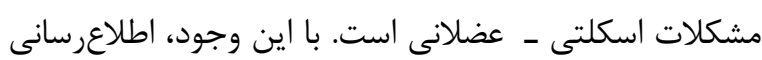

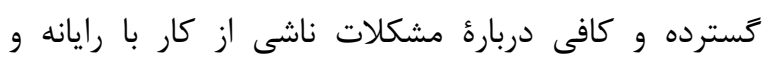

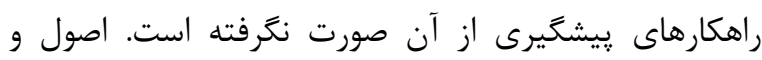
راهكارهاى ساده و ضرورى بهداشتى و اركونوميكى كار با رايانه

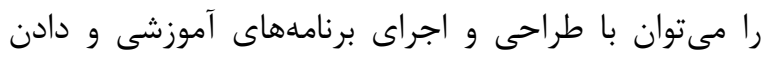

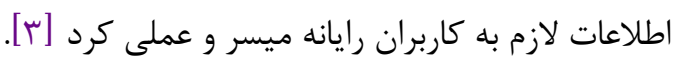

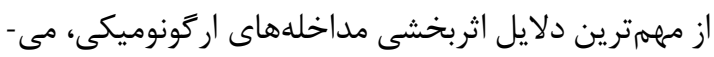

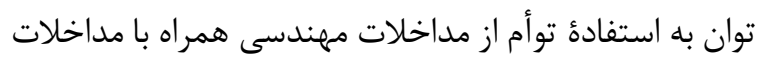

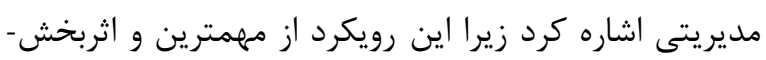

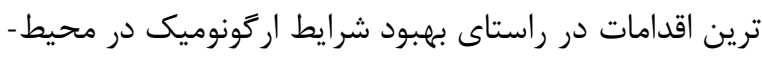

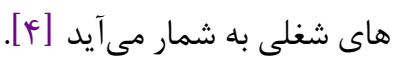

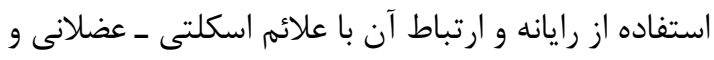

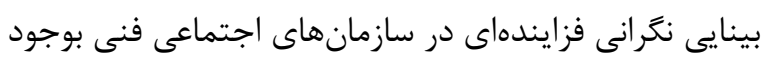

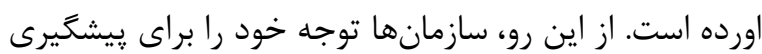

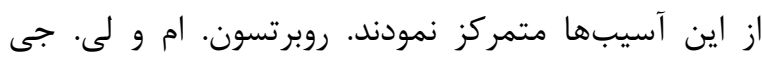

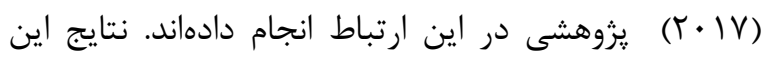
مطالعه نشان داد كه مداخله ار كونومى در سطح كلان، مى اتواند

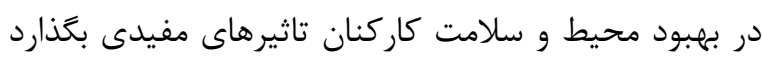

جوبينه و همكاران (Y (I I) با توجه به يافتهها، فراوانى

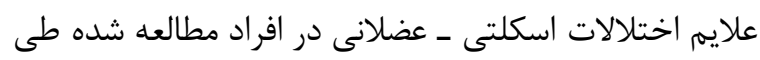

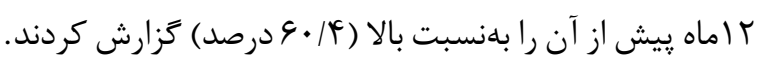

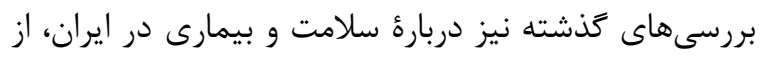

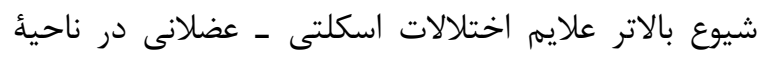

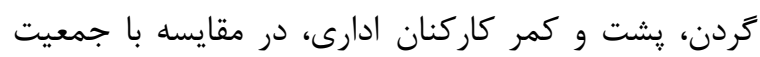

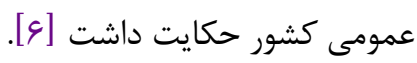

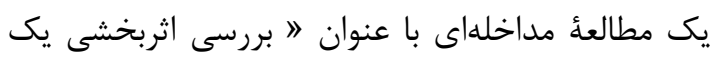

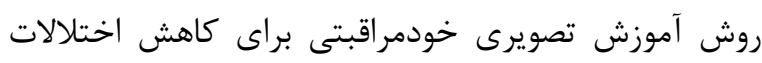

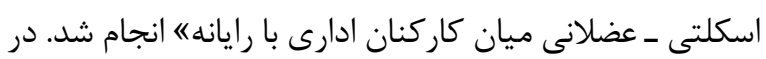

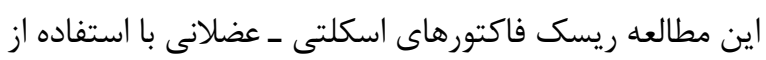

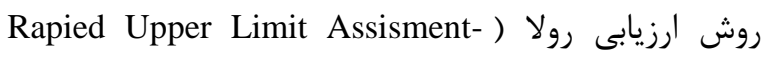
(RULA

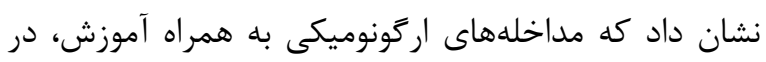

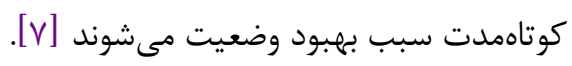

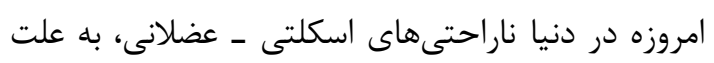

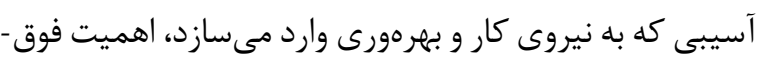
العادهاى دارند. به همين سبب ضروي كارو بهرى است كه مطالعات 


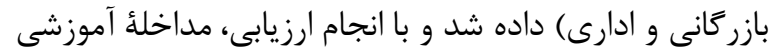
و مداخله مهرندى و تأمين تجهيزات لازم براى انجام

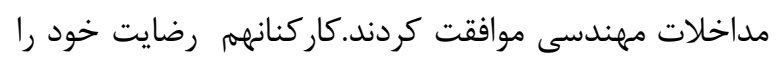

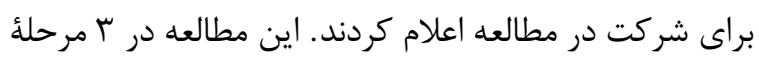

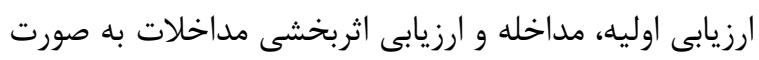

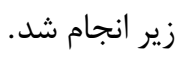

\section{فاز اول ــارزيابى اولد اليه}

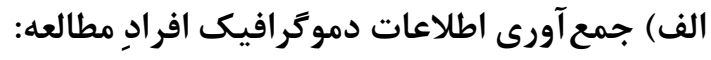

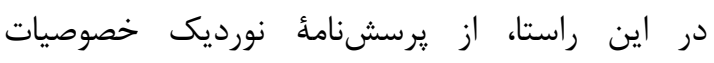
دموكرافيك استفاده شد كه براى اين منظور طراحى شده بود و در آن متغيرهاى سن، جنس، قد، وزن و سابقُ كارى كنجانده

شده بود.

\section{ب) بر رسى شيوع ناراحتى هاى اسكلتى ـ عضلانى:}

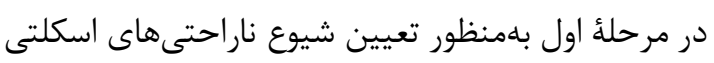
ـ عضلانى از يرسشنامهُ نورديك استفاده شد. اين :برسشنامه r بخش عمومى و اختصاصى دارد كه با توجه بـ اهداف مطالعه، فقط قسمت عمومى آن بررسى شد. همجنين علت ايجاد ناراحتىها (آيا ناراحتى ايجادشده ناشى از كار است يا خير؟)

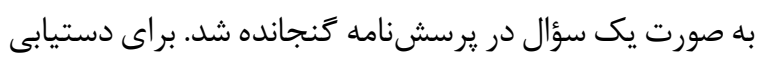

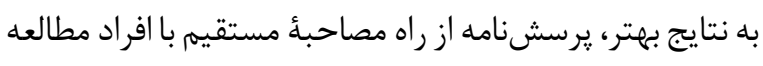

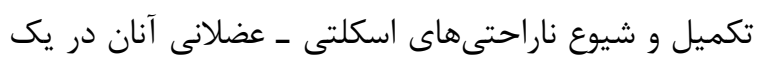

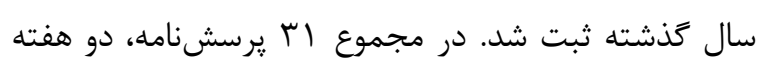

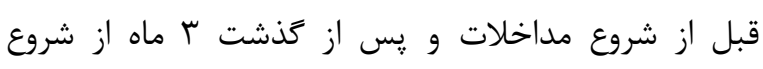
مداخلات بين كليه افراد توزيع شد كه يرسشنامهها رات رات تكميل و به محقق بازگرداندند. فاز دوم - مداخله

يس از بررسى ايستخاههاى كارى با استفاده از روش "روز مداخها"

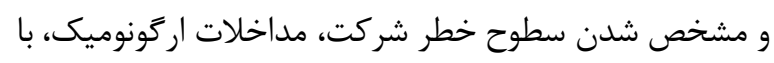

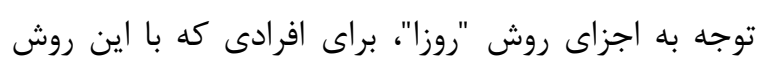

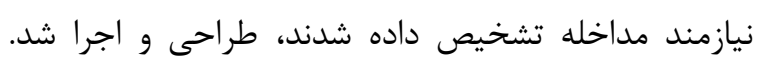

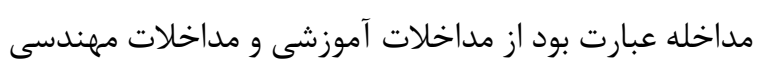
كه به صورت زير اجرا شد: الف) مداخلات آموزشى:

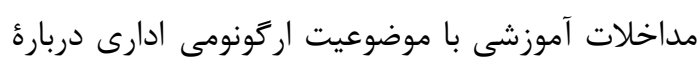

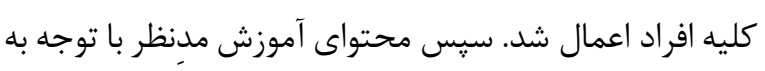

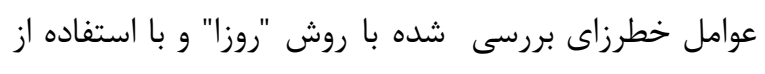

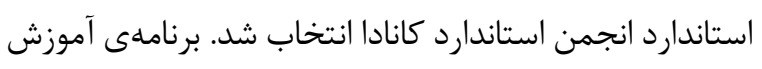
عبارت بود از نحؤ تنظيم و جيدمان وسايل روى سطح ميز
كاربرد موثر روش "روزا" در يزوهش هاى مخت مختلف ثابت

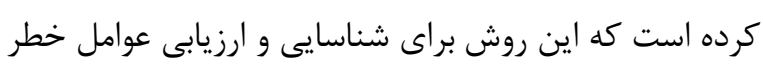

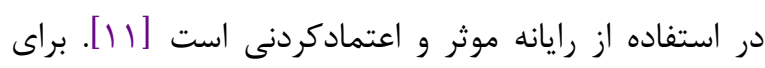

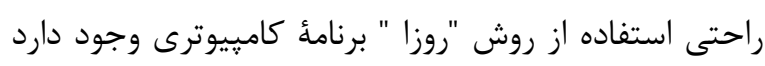

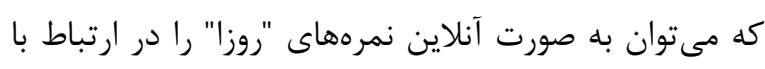

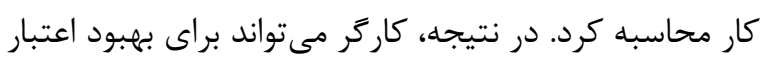

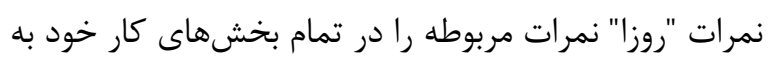

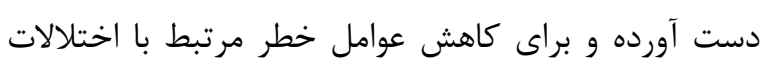

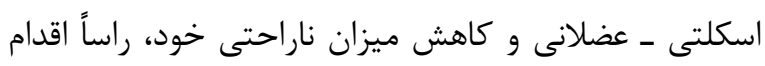

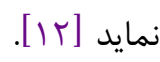

مطالعات انجام شده در ايران نشان مىدهد كه كار مداوم

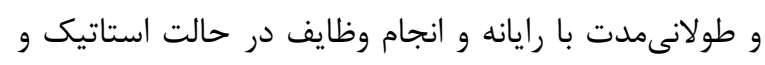

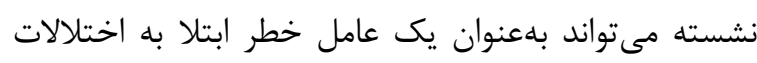
اسكلتى ـ عضلانى شناخته شود. در ضمن نتايج مطالعات نشان

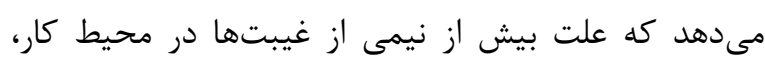

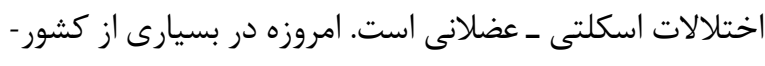

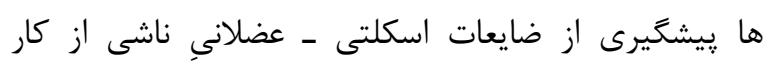

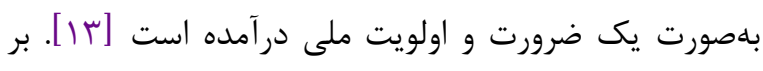

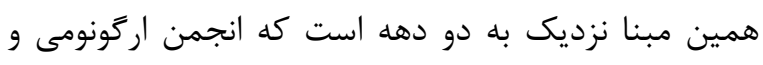

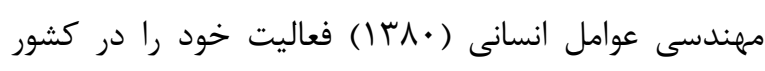

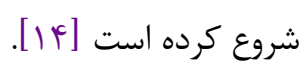

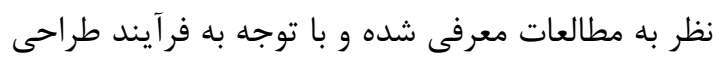

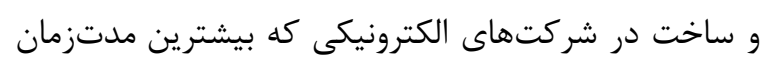

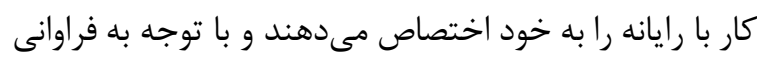

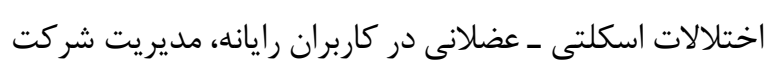

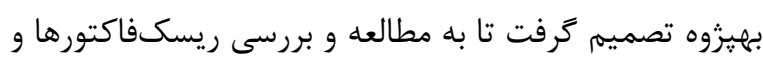

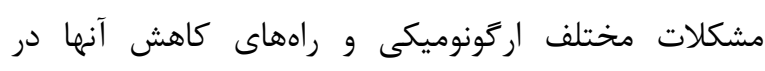
جهار جوب اين يزوهش بيردازد.

$$
\text { روش كار }
$$

اين مطالعه توصيفى ـ تحليلى به صورت مداخلهاى در سال

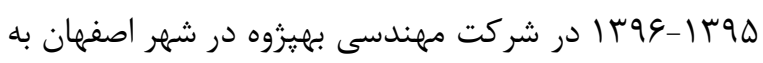

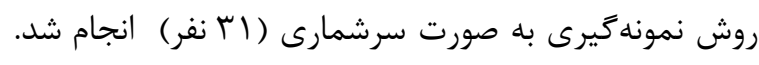

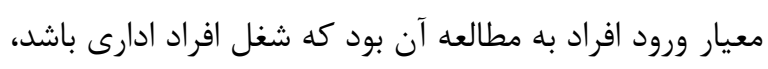
در روز حداقل r ساعت و بيشتر با رايانه كار كنند و سابقة كار حداقل يك سال و بالاتر داشته باشند.

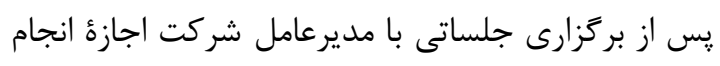

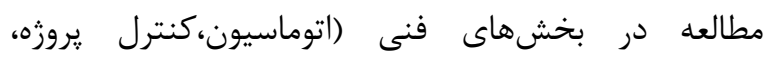
الكتروشيمى، طراحى الكترونيك و ساخت) و ادارى (مالى، لئ، 


\section{فاز سوم ـ ارزيابى اثربخشى مداخلات}

يس از كذشت سه ماه از شروع مداخلات (آموزشى و

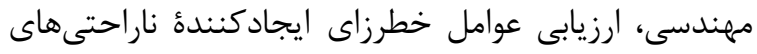

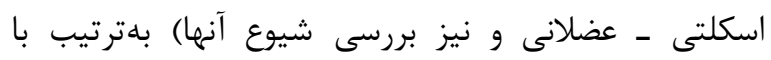
يرسشنامئ نورديك و روش "روزا" در شركت بررسى شده و ميزان اثربخشى مداخلات اركونوميكى در مقايسه با قبل از نداز مداخلات تعيين و دادهها مقايسه شدند.

\section{روش تجزيه وتحليل دادهها}

براى تجزيه و تحليل توصيفى و استنباطى دادهها از نرمافزار SPSS و براى مقايسُٔ نسبت شيوع نار احتىهاى اسكلتى

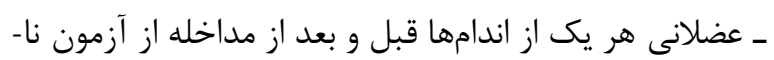
يارامترى آمارى مكنمار استفاده شد. به منظور مقايسٔ

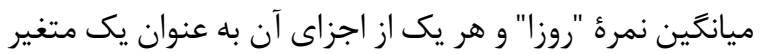

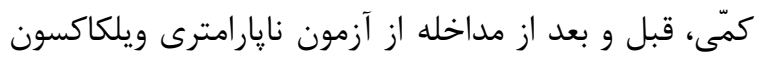

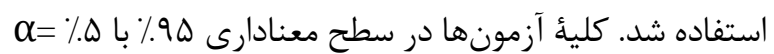

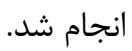

يافته ها

خصوصيات دموكرافيك افراد بررسى شده در جدول 1

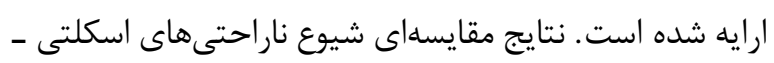

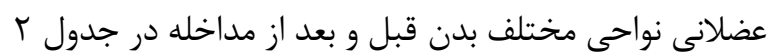

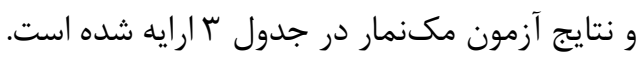

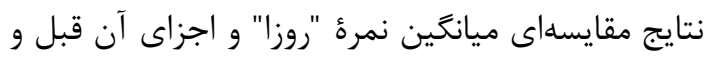

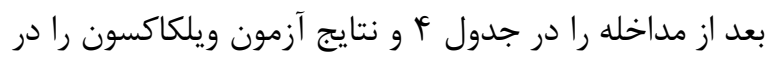
جدول ه مى توان مشاهده كرد. تفاوت معنادارى بين ميانكين

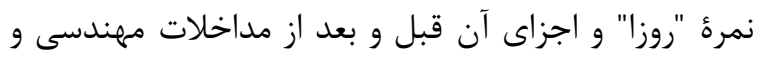

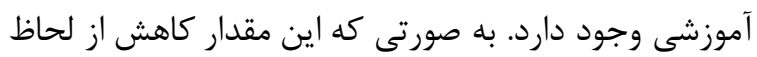

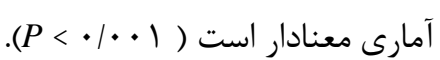

كار، شناسايى يوسجرهاى خنثى و نامناسب، نحوء تنظيم صندلى و ايجاد يوسجرهاى مناسب حين كار روى صندلى إلى،

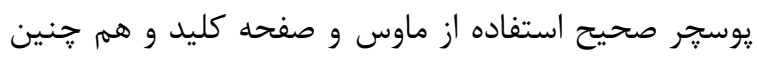
نحوئ قراركيرى مناسب ماوس و صفحه كليد آن روى سطح كار، نحوه صحيح استفاده از موس و صفحه كليد، نحؤ

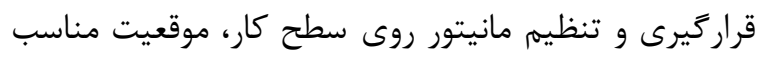
قرار كيرى تلفن نسبت به موقعيت فرد، نحوء استفادئ صحيح

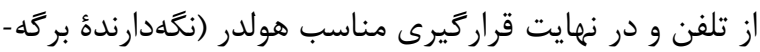

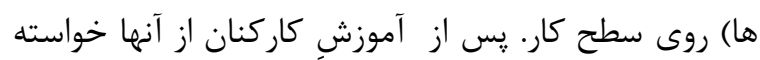
شد، محل كار خود را با توجه به استانداردهاى ارايه شده ارن تنظيم كنند. ذكر كردنى است كه در دورة مطالعه، آموزشهاى آراى جهره به جهره در رابطه با سؤالهاى احتمالى براى كلئ كاركنان حاضر در شركت، بلمنظور تنظيم ايستگاه كارى انجام كرفت

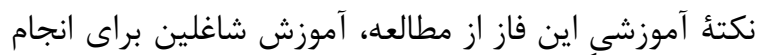

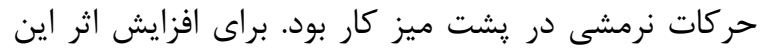

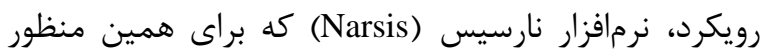
طراحى شده است، روى رايانٔ كليئ شاغلين نصب شد. اين نرم افزار در زمانهاى مختلف هر روز كارى، به صورت خودكار

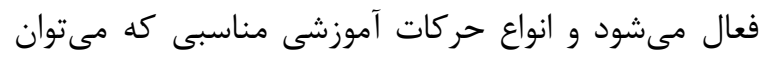

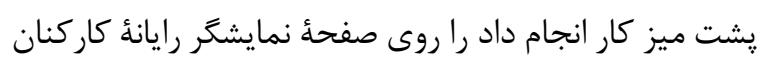
نمايش مى دهد و به آنان يادآورى مى كند.

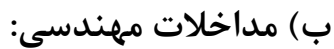

اين مداخله عبارت بود از تعلات مهندسي

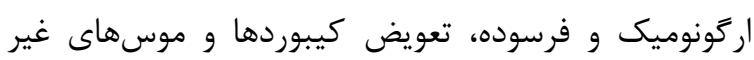

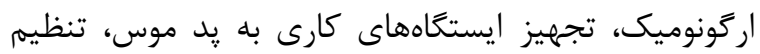

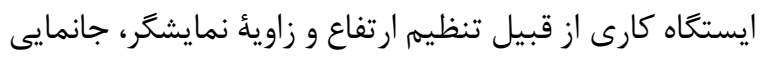

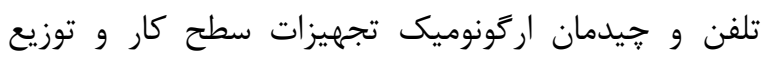
زيريايى اركونوميك براى كاركنان.

جدول ا. مشخصات دموكر افيك

\begin{tabular}{|c|c|c|c|c|c|c|}
\hline تعداد نمونه ها & سابقه كار & قد & وزن & سن & آماره & 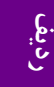 \\
\hline r & $1 \cdot 10$ & IVT/T & $V I / V$ & $r r / q$ & ميانكَين & 1 \\
\hline r & $N / 1$ & $V / F$ & $1 \cdot 11$ & $N / F$ & انحراف معيار & $r$ \\
\hline r & 1 & $1 \Delta \Delta$ & $\Delta \Delta$ & 19 & حداقل & $r$ \\
\hline r & $r f$ & INT & 90 & $\Delta V$ & حداكثر & f \\
\hline
\end{tabular}


جدول r. فراوانى اختلالات اسكلتى ـ عضلانى

\begin{tabular}{|c|c|c|c|c|c|}
\hline \multicolumn{2}{|c|}{ بعد از مداخله } & \multicolumn{2}{|c|}{ قبل از مداخله } & \multirow{2}{*}{ ناحيه } & \multirow{2}{*}{8} \\
\hline درصد & فراوانى & درصد & فراوانى & & \\
\hline $9 / 0$ & r & $r \Delta / r$ & If & كردن & 1 \\
\hline$r / r$ & 1 & $r \Delta / \Delta$ & 11 & شانهها & $r$ \\
\hline . & . & . & . & آرنجها & $r$ \\
\hline . & . & rq & 9 & مجدست & p \\
\hline $9 / 0$ & r & rN/V & ir & فوقانى يشت & $\Delta$ \\
\hline 1914 & $\Delta$ & $r \Delta / T$ & if & كمر & 9 \\
\hline . & . & rq & 9 & باسن و ران & v \\
\hline$r / r$ & 1 & rq & 9 & زانوها & $\wedge$ \\
\hline $9 / 7$ & r & $9 / 0$ & r & مج پا & 9 \\
\hline
\end{tabular}

\begin{tabular}{|c|c|c|c|c|c|c|c|c|}
\hline & & & & & & & \multicolumn{2}{|c|}{ مدول r. نتايج آزمون مك نمار } \\
\hline & كردن & شانه & مهج دست & فوقانى يشت & كمر ل كر & باسن و ران & زانو & مجز باها \\
\hline تعداد & ri & ri & m & r & m & M & rI & m \\
\hline $\begin{array}{l}\text { Exact Sig. } \\
\text { (2-tailed) }\end{array}$ & $\cdot \cdot / . r r$ & $\cdot .1 .9$ &.$+ / . r$ & +.1 .09 &..$/ .14$ & $\cdot \cdot / \cdot r$ & $+\cdot|\cdot r|$ & $\cdot \cdot / \Delta \cdot \cdot$ \\
\hline
\end{tabular}

جدول F. فراوانى ريسك فاكتور هاى ارتونوميكى از روش ROSA

\begin{tabular}{|c|c|c|c|c|c|c|c|c|c|}
\hline \multicolumn{4}{|c|}{ بعد از مداخله } & \multicolumn{4}{|c|}{ قبل از مداخله } & \multirow[b]{2}{*}{ ارزيابى } & \multirow[b]{2}{*}{ رديف } \\
\hline حداكثر & حداقل & معيار & ميانكَين & حداكثر & حداقل & معيار & ميانكَين & & \\
\hline F & 1 & .191 & $r / .9$ & $\wedge$ & 1 & $1 / N 1$ & $r / r q$ & صندلى & 1 \\
\hline$r$ & . & $\cdot / v$ & $1 / \lambda$ & f & . & .190 & $r / F \mid$ & نمايشكر & r \\
\hline r & . &.$/ 9 T$ & . & f & . & $1 / \cdot 0$ & $\cdot / V V$ & تلفن & $r$ \\
\hline$r$ & . & .109 & $1 / V 1$ & $\Delta$ & . & 1/Tr & $r / F \wedge$ & موس & f \\
\hline$r$ & . & $\cdot / \mathrm{AV}$ & .19 & $\Delta$ & . & $1 / \pi r$ & $1 / r \wedge$ & صفحه كليد & $\Delta$ \\
\hline f & 1 & $.19 \mathrm{~V}$ & T/TY & $\wedge$ & 1 & $1 / 90$ & r/ra & ROSA & 9 \\
\hline
\end{tabular}

جدول ه. نتايج آزمون ويلكاسون آزمون آمارى الف

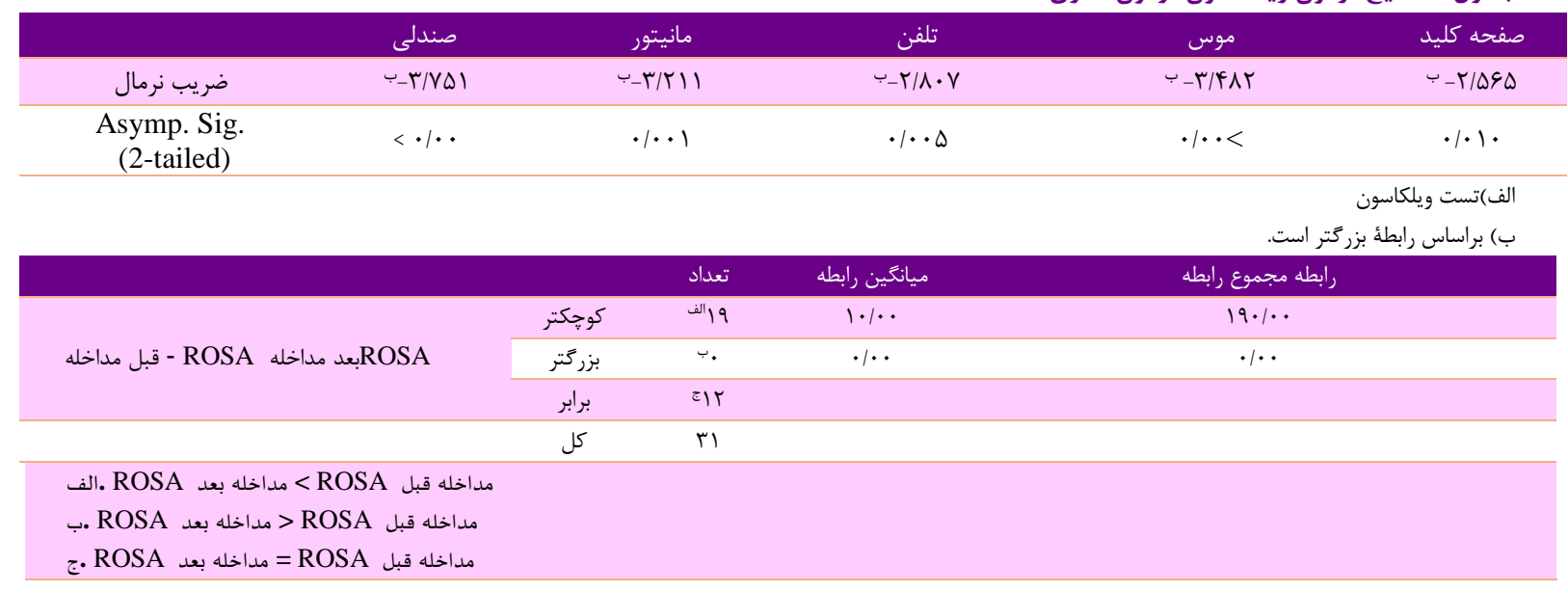

\begin{tabular}{|c|c|}
\hline ضريب نرمال & 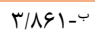 \\
\hline Asymp. Sig. (2-tailed) & $<\cdot /$. \\
\hline
\end{tabular}

\footnotetext{
الف) تست ويلكاكسون

ب) توزيع دوتايى استفاده شده است
} 
اظهارى (يرسشناملُ نورديك) اشاره كرد. زيرا خود اظهارى

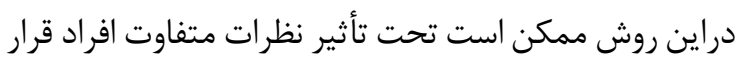

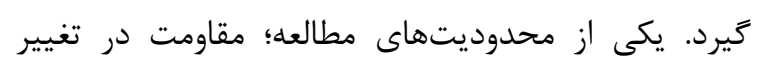

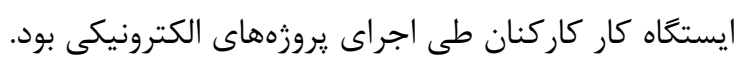

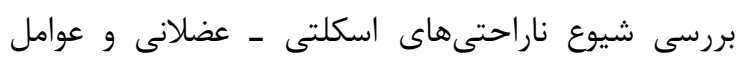

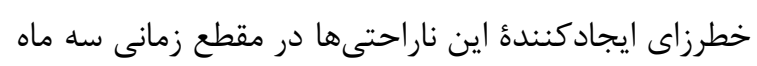

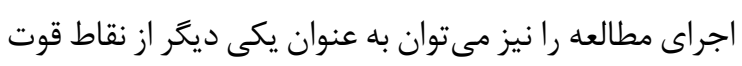
مطالعه لحاظ كرد زيراطبق نظر نصيرى و همكاران (

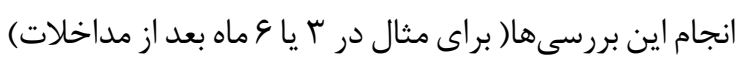

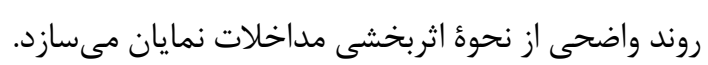

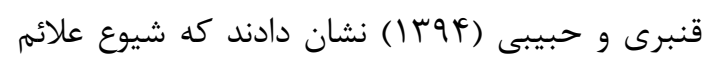

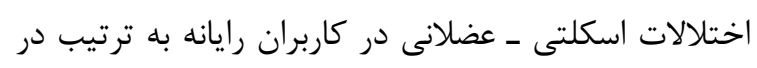

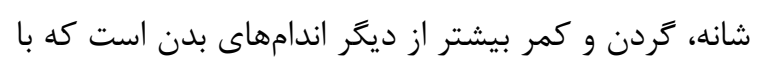

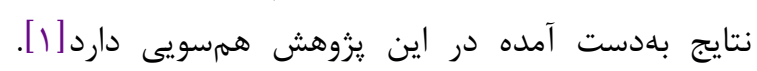

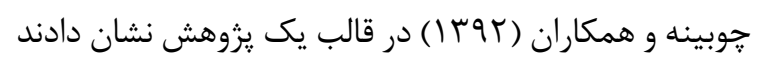

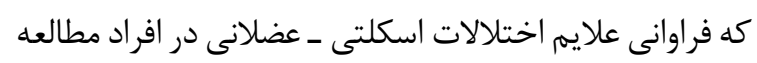

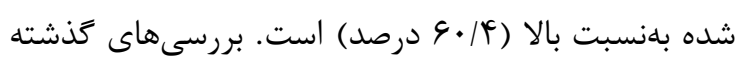

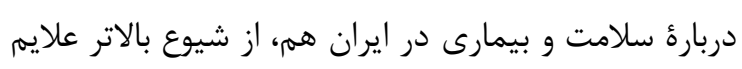

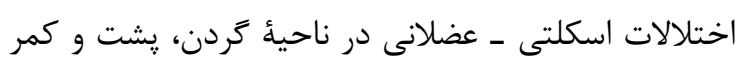

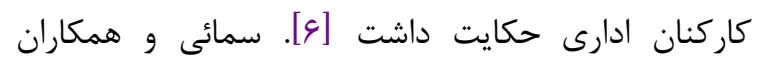

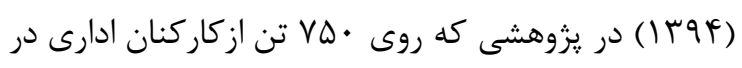

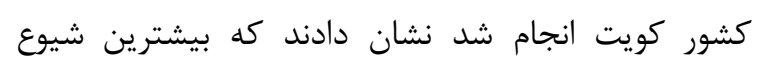

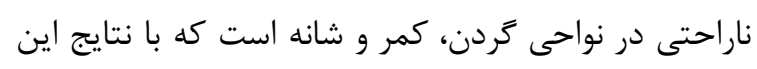

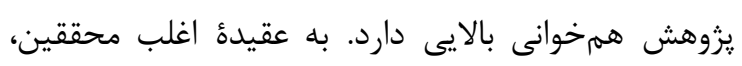

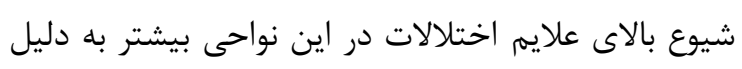

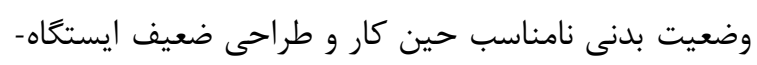

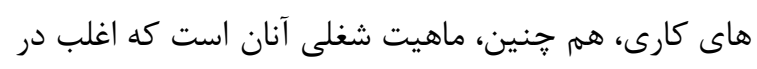

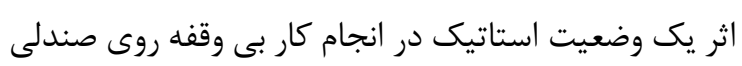

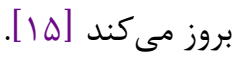

\section{نتيجه كيرى}

شِ إز كذشت سه ماه از اجراى مداخلات، در وضعيت

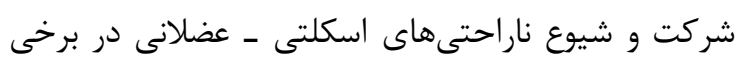

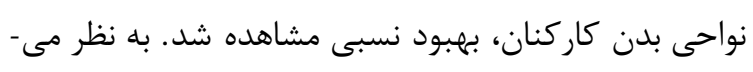

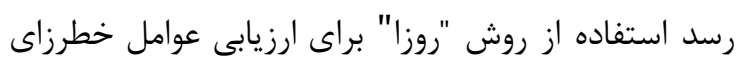

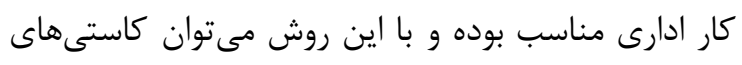

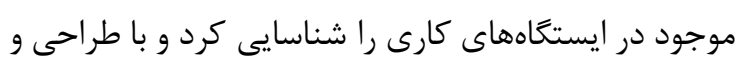

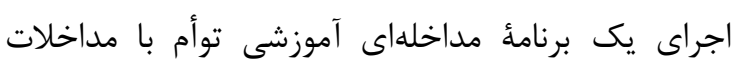
مهندسى منطبق با اجزاى اين روش، براى رفع نواقص اقدام

بررسىها نشان مىدهد كه كمترين فراوانى ضايعه براى

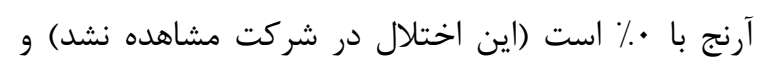

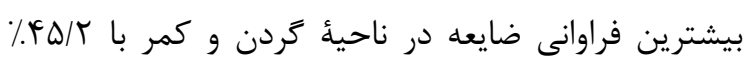

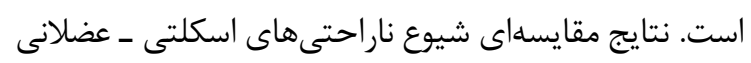

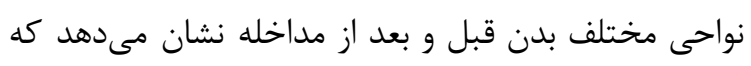

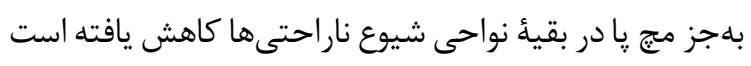

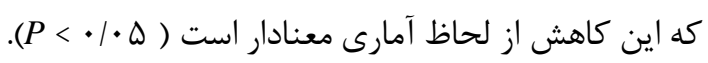

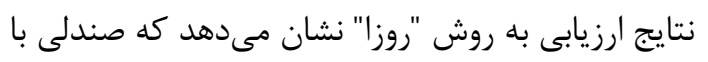

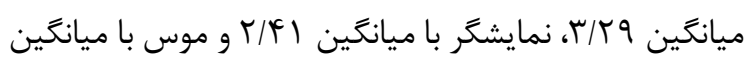
T/F

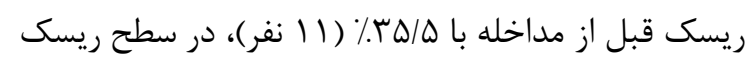

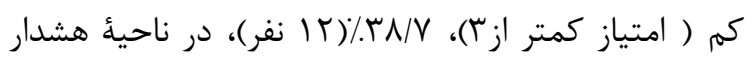

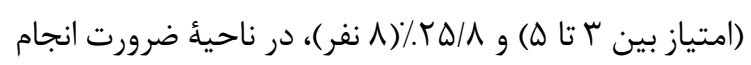

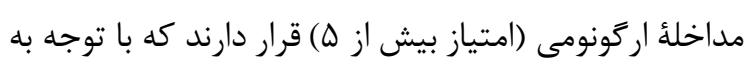

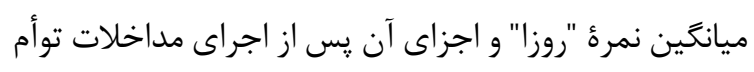

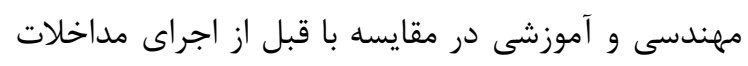

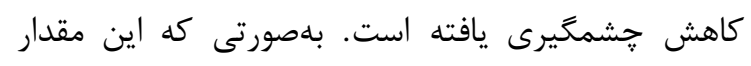

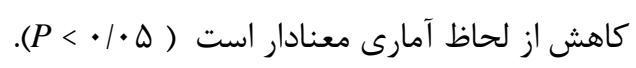

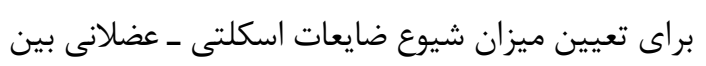

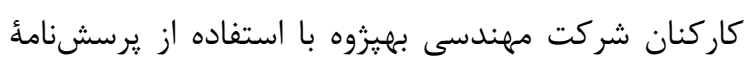

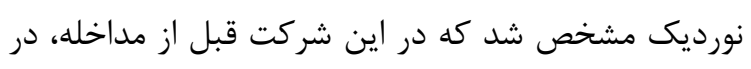
ناحية آرنج هيجَّونه مشكلى وجود ندارد. در ناحيئ كمر،

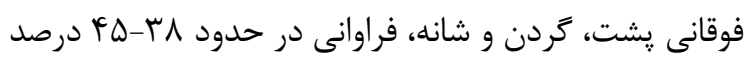

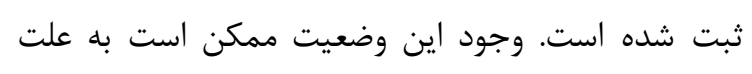
طراحى نامناسب محيط كار در شركت باشد. كار ادارى به وضه

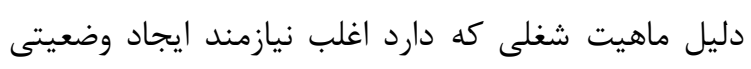

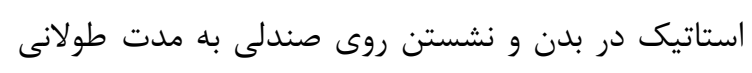

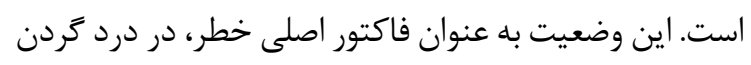
معرفى شده است. يكى از عوامل مههم در كسب نتايجِ حاصل از استفاده

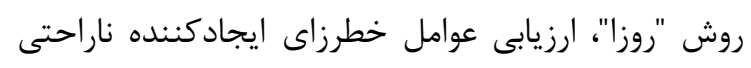

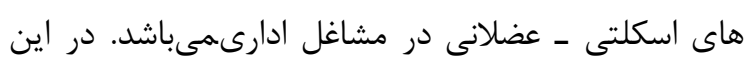

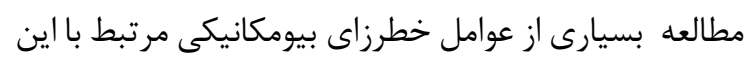

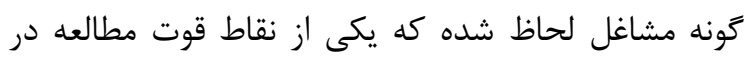

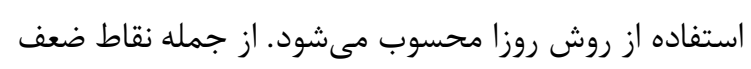

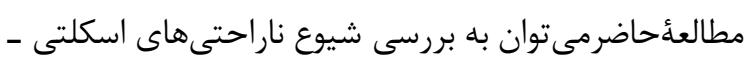

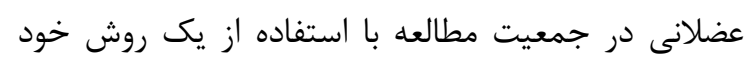




$$
\begin{aligned}
& \text { تقدير و تشكر } \\
& \text { از مديريت شر كت مهندسى بهيززوه و كاركنان محترم آن }
\end{aligned}
$$

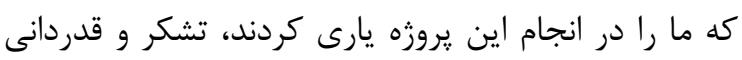

$$
\begin{aligned}
& \text { مى كنيه. } \\
& \text { تعارض منافع } \\
& \text { بين نويسند }
\end{aligned}
$$

\section{References}

1. Ghanbary-Sartang A, Habibi E. Evaluation of musculoskeletal disorders to method Rapid Office Strain Assessment (ROSA) in computers users. Int J Prev Med. 2015;2(1):47-54.

2. Habibi E, Karimi S, Hassan-Zadeh A. Evaluation of ergonomic risk factors by OCRA method in assembly industry. Iranian Occupational Health. 2008;5(1):70-6.

3. Jahanimoghadam $\mathrm{F}$, Abdolalizadeh $\mathrm{M}$. Ergonomics, Musculoskeletal Disorders, and Computer Work. Journal of Health and Biomedical Informatics. 2016;3(2):145-54.

4. Nasiri I, Motamedzade M, Golmohammadi R, Faradmal J. Assessment of risk factors for musculoskeletal disorders using the Rapid Office Strain Assessment (ROSA) Method and implementing ergonomics intervention programs in Sepah Bank. Journal of Health and Safety at Work. 2015;5(2):47-61.

5. Robertson MM, Huang YH, O’Neill MJ, Schleifer LM. Flexible workspace design and ergonomics training: Impacts on the psychosocial work environment, musculoskeletal health, and work effectiveness among knowledge workers. Appl Ergon. 2008;39(4):482-94.

https://doi.org/10.1016/j.apergo.2008.02.022 PMid:18462704

6. Dehghan N, Choobineh AR, Hasanzadeh J. Interventional ergonomic study to correct and improve working postures and decrease discomfort in assembly workers of an electronic industry. Iran Occupational Health. 2013;9(4):71-9.

7. Taieb-Maimon M, Cwikel J, Shapira B, Orenstein I. The effectiveness of a training method using self-modeling webcam photos for reducing musculoskeletal risk among office workers using computers. Appl Ergon. 2012;43(2):376-85.

https://doi.org/10.1016/j.apergo.2011.05.015 PMid:21745654

8. Sadra Abarghouei N. Comprehensive ergonomic interventions for improving

$$
\begin{aligned}
& \text { كرد. از طرفى افزايش آكاهى شاغلين در رابطه با عوامل } \\
& \text { خطرزاى ارگونوميك كار ادارى و نحوه صحيح جيدمان } \\
& \text { تجهيزات، مىتواند ايستخاه كارى را به دست خِود كورد كاركنان } \\
& \text { تنظيم كند و در نتيجه سبب بهبود شرايط شود. }
\end{aligned}
$$

ergonomic conditions in an automobile spare part manufacturing plant: A case study. Journal of Ergonomics. 2015;3(2):1-13.

9. Kalte HO, Hekmatshoar R, Taban E, Faghih MA, Yazdani Aval M, Shokri S. Effects of an ergonomic training program on the reduction of musculoskeletal disorders. J Sabzevar Univ Med Sci. 2016;23(1):58-65.

10. Chiman Saeidi, Dastaran S, Musavi S. Evaluation of the Risk Factors of Musculoskeletal Disorders and its Relation to the Workload of Employees at 118 Call Center in Sanandaj, Iran. J Health Dev. 2016;5(2):11021.

11. Sonne M, Villalta DL, Andrews DM. Development and evaluation of an office ergonomic risk checklist: ROSA-Rapid office strain assessment. Appl Ergon. 2012;43(1):98108.

https://doi.org/10.1016/j.apergo.2011.03.008 PMID:21529772

12. Sonne M, Andrews DM. The Rapid Office Strain Assessment (ROSA): Validity of online worker self-assessments and the relationship to worker discomfort. Occupational Ergonomics. 2011;10(3):83-101.

13. Choobineh AR. Posture Assessment Methods in Occupational Ergonomics. Hamedan: Fanavaran Publishing House; 2014. p.1-12.

14. Sadra Abarghouei N. Ergonomics (fitting of work, environment and machine with human).Yazd: Yazd University Publishing House; 2016. p.1-9.

15. Samaei S I, Tirgar A, Khanjani N, Mostafaee M, Bagheri Hosseinabadi M, Amrollahi M. Assessment of ergonomics risk factors influencing incidence of musculoskeletal disorders among office workers. Journal of Health and Safety at Work. 2015;5(4):1-12. 